\title{
Fate of the preserved aortic root after treatment of acute type A aortic dissection: 23-year follow-up
}

\author{
Angelo M. Dell'Aquila, MD, Giovanni Concistrè, MD, Alina Gallo, MD, Stefano Pansini, MD, \\ Alessandro Piccardo, MD, Giancarlo Passerone, MD, and Tommaso Regesta, MD
}

Objective: The objective of this study was to examine the fate of the native aortic root after replacement of the ascending aorta to treat acute type A aortic dissection.

\begin{abstract}
Methods: Between June 1985 and January 2010, 319 consecutive patients (mean age, $63 \pm 11$ years) with acute type A aortic dissection underwent replacement of the ascending aorta with preservation of the aortic root. The aortic valve was also replaced in 21 of these patients $(7 \%)$. The intervention was extended to the aortic arch in 210 patients $(66 \%)$, of whom $173(54 \%)$ underwent hemiarch replacement, and $37(12 \%)$, total arch replacement.

Results: There were 109 (34\%) in-hospital deaths. Of the 210 discharged patients, survival was $95 \%, 58 \%$, and $27 \%$ at 1,10 , and 23 years, respectively. Freedom from reoperation on the proximal aorta was reported by $97 \%$, $92 \%$, and $82 \%$ patients at 5,10 , and 23 years, respectively. Twelve patients were reoperated for aortic root dilatation and 2 died during reoperation. Univariate and multivariate Cox regression analyses revealed that significant risk factors for proximal reoperation were age $<60$ years $(P=.005$; relative risk, 1.94$)$ and Marfan syndrome $(P=.011$; relative risk, 2.76). At follow-up, 15 patients $(11 \%)$ had an aortic root diameter of $>45 \mathrm{~mm}$, but they were not reoperated.
\end{abstract}

Conclusions: For acute type A aortic dissection, replacement of the ascending aorta with root preservation shows long-term effectiveness with low reoperation and aortic root dilatation rates. (J Thorac Cardiovasc Surg 2013;146:1456-60)

During emergency surgery for acute type A aortic dissection (AAD), the major operative decisions include the extent of aortic resection to be performed and the use of an appropriate surgical procedure when the dissection involves the aortic root. Supracoronary replacement of the ascending aorta with root reconstruction is one of the most commonly adopted conservative approaches used during surgery for AAD. However, preservation of the aortic structures below the sinotubular ridge might predispose the patient to the formation of a proximal aneurysm that will then require reoperation on the aortic root and/or the aortic valve during the late postoperative period. ${ }^{1,2}$ The more aggressive approach of total root replacement prevents future aneurysmal formations and recurrent dissection of the aortic root, ${ }^{2,3}$ but the reduced tissue quality of the dissected aorta increases the technical complexity of the procedure with possible additional operative risk. ${ }^{2}$ Valve-sparing root replacement has shown excellent results in patients operated electively for aortic root ectasia, but few data are available

From the Division of Cardiac Surgery, San Martino University Hospital, University of Genova, Genova, Italy.

Disclosures: Authors have nothing to disclose with regard to commercial support.

A.M.D.A. and G.C. contributed equally to this study and should be considered co-first authors.

Received for publication April 27, 2012; revisions received July 18, 2012; accepted for publication Sept 20, 2012; available ahead of print Oct 18, 2012.

Address for reprints: Giovanni Concistrè, MD, L. go Rosanna Benzi 10, 16132,

Genova, Italy (E-mail: gioconci@libero.it).

0022-5223/\$36.00

Copyright (c) 2013 by The American Association for Thoracic Surgery

http://dx.doi.org/10.1016/j.jtcvs.2012.09.049 for this technique in an emergency setting during surgery for $\mathrm{AAD}$, and studies that have been performed have had short follow-up times. ${ }^{4-6}$ In view of these controversies, we determined the long-term results of supracoronary replacement of the ascending aorta with native aortic root preservation in patients with $\mathrm{AAD}$.

\section{METHODS \\ Patients}

Between June 1985 and January 2010, 373 patients underwent surgical treatment for AAD at San Martino University Hospital of Genoa, Italy. All patients were operated on in an emergency setting soon after hospital admission without delaying the surgical intervention. The majority of patients was operated on within 24 hours after the onset of symptoms. Three hundred nineteen of these patients $(85.5 \%)$ underwent replacement of the ascending aorta with preservation of the native aortic root. The diagnosis of AAD was based either on transthoracic and/or transesophageal echocardiography, computed tomography, or operative exploration, all in conjunction with medical history. Inclusion criteria were supracoronary replacement of the ascending aorta with or without aortic valve replacement. Patients underwent surgical reconstruction of 1 coronary or noncoronary sinus by tailored graft; patients who underwent root replacement using the David, Yacoub, or Bentall procedure were excluded from the study. Outcomes analysis was approved by the local ethics committee, and individual consent was waived. Baseline patient characteristics and predisposing factors for aortic dissection are presented in Table 1.

\section{Surgical Findings and Operative Data}

Intraoperative findings confirmed the diagnosis of $\mathrm{AAD}$ in all patients. The site of the proximal intimal tear was the ascending aorta in 243 patients $(76 \%)$ and the aortic arch in 63 patients $(20 \%)$. In 13 patients $(4 \%)$, the intimal tear was in the descending aorta ( 6 patients) or could not be identified 


\section{Abbreviations and Acronyms}

$\mathrm{AAD}=$ acute type $\mathrm{A}$ aortic dissection

DHCA $=$ deep hypothermic circulatory arrest

$\mathrm{RR} \quad=$ relative risk

(7 patients). Two hundred ten patients $(66 \%)$ underwent partial or total arch replacement. Additional procedures included coronary artery bypass grafting to treat associated dissection of the right coronary ostium in 20 patients $(6 \%)$ and mitral valve repair in 2 patients $(0.6 \%)$. Mean cardiopulmonary bypass time was $183 \pm 70$ minutes (range, $89-505$ minutes) and mean ischemic cardiac time was $110 \pm 40$ minutes (range, 27-201 minutes). Mean circulatory arrest time for patients with arch replacement and open distal anastomoses was $36 \pm 21$ minutes (range, 12-94 minutes). Mean temperature used for deep hypothermic circulatory arrest (DHCA) was $23^{\circ} \mathrm{C} \pm$ $1.2^{\circ} \mathrm{C}$. During the first phase of our center's experience, circulatory arrest was performed in deep hypothermia. Subsequently, we used moderate hypothermia with a selective antegrade cerebral perfusion technique (Table 2).

\section{Operative Technique}

The surgeons and some minor aspects of the surgical technique varied during the study period. All operations were performed on an emergency basis as soon as the diagnosis had been ascertained. After aortic crossclamp, the ascending aorta was opened and the heart was arrested by direct anterograde administration of blood cardioplegia into both coronary ostia. Our general approach included supracoronary replacement of the ascending aorta with a Dacron prosthesis. The arch was first exposed under DHCA. If an intimal tear was present or extended to the aortic arch, we replaced the arch completely or in part. If it was unnecessary to replace the arch, an open distal aortoprosthesis anastomosis was performed. The proximal ascending aortic procedure was then performed during the subsequent rewarming period as follows. After careful inspection of the aortic root and valve, all the dissected tissue just above the commissures was removed, and a tailored strip of Teflon felt was inserted between the dissected aortic layers. Based on surgeon preference, surgical glue was applied to achieve complete obliteration of the entire space of the proximal dissection. The Dacron graft was then sutured inside the reconstructed aortic root using a continuous 4-0 Prolene suture. During the early series, intraoperative transesophageal echocardiogram was not available; therefore, root diameter root was measured directly after proximal repair. In general, we accepted a root diameter of $<38 \mathrm{~mm}$. Assessment of valve competency was performed through direct observation of cusp cooptation. Later in the series, when intraoperative transesophageal echocardiogram was available, we generally accepted a residual aortic insufficiency of $\leq 2+/ 4+$. In case of more regurgitation, the aortic valve was replaced.

\section{Follow-up}

Follow-up data were obtained from telephone interviews with the surviving patients or with families and referring physicians, or from direct examination at San Martino Hospital. Questions addressed actual functional status and transthoracic echocardiogram examination findings. Patients unable to attend our hospital sent in their transthoracic echocardiogram reports. Clinical follow-up was closed in September 2010 and was completed by $97 \%$ (311/319); at study end, 137 patients were alive. Mean follow-up was 12.6 years (range, 8 months-23.3 years). Transthoracic echocardiogram reports were available for 99 of 137 survivors $(72 \%)$ at latest follow-up.

\section{Statistical Analysis}

The design of the study was retrospective, and analyses were performed with JMP statistical analysis software (SAS Institute, Inc, Cary, NC).
Continuous variables are presented as mean $\pm \mathrm{SD}$ and categoric variables are expressed as frequencies. Comparison between variables was performed by means of a $t$ test, $\chi^{2}$ test, or Fisher exact test when appropriate. Survival and event-free estimates were determined by the Kaplan-Meier method and are expressed as the proportion \pm standard error. Possible risk factors for reoperation including clinical characteristics such as age, sex, hypertension, diabetes mellitus, peripheral vascular disease, and Marfan syndrome, and surgical variables such as ischemic time, cardiopulmonary bypass time, DHCA time, and technique performed, were entered into the model. Diagnosis of Marfan syndrome included wrist and thumb sign, ectopia lentis, skin striae, and family history with Marfan syndrome. ${ }^{7}$ Additional information or confirmation of Marfan syndrome was obtained from relatives, referring hospital, and family physicians. A univariate analysis was performed first. Variables with $P \leq .2$ were included in a multivariable model for Cox regression analysis with stepwise selection to determine the independent predictors of root reoperation. A $P$ value $<.05$ was considered statistically significant.

\section{RESULTS}

\section{Survival and Proximal Reoperations}

In-hospital mortality was 34\% (109 patients) and there were 65 late deaths $(22 \%)$. Causes of in-hospital mortality were low output syndrome in 37 patients $(33.9 \%)$, bleeding in 17 patients $(15.6 \%)$ multiple-organ failure in 44 patients $(40.4 \%)$, and neurologic events 11 patients $(10.1 \%)$. Thirtyday mortality during the last period, between 2008 and 2010, was $15.3 \%$. Of the 210 discharged patients, survival was $95 \% \pm 1.5 \%, 82 \% \pm 3 \%, 58 \% \pm 4.5 \%, 51 \% \pm 5 \%$, and $27 \% \pm 9 \%$ at $1,5,10,15$, and 20 years, respectively (Figure 1). At latest follow-up, reoperation was required by 15 patients $(10.8 \%), 3$ of whom received isolated aortic valve replacement and 12 of whom ( $8.7 \%$ of 137 survivors) underwent aortic root replacement. Four reoperated patients $(33.3 \%)$ had Marfan syndrome and underwent root replacement after a mean interval of 13 years (range, 5.6-20.3 years). Indications for proximal reoperations included isolated aortic root dilatation (mean diameter, $5.2 \pm 2.3 \mathrm{~mm}$ ) in 2 patients and root dilatation (mean diameter, $5.4 \pm 2.1$ $\mathrm{mm})$ with associated aortic regurgitation $(>2+)$ in $10 \mathrm{pa}-$ tients. The Bentall procedure was used in all instances. The in-hospital mortality rate was $16.67 \%$ (2 patients). One patient died from multiorgan failure on the sixth postoperative day and 1 patient died from acute mesenteric ischemia on the third postoperative day. Freedom from reoperation on the proximal aorta was reported by $99 \% \pm$ $0.5 \%, 97 \% \pm 1 \%, 93 \% \pm 2 \%, 83 \% \pm 6 \%$, and $66 \% \pm$ $15 \%$ at $1,5,10,15$, and 23 years, respectively (Figure 2 ).

\section{Risk Factors for Native Preserved Aortic Root Dilatation and Echocardiographic Follow-up}

Univariate and multivariate Cox regression analyses revealed that significant risk factors for proximal reoperation were age $<60$ years $(P=.005$; relative risk $[\mathrm{RR}], 1.94)$ and Marfan syndrome $(P=.011 ; \mathrm{RR}, 2.76)$. Echocardiographic follow-up among survivors showed a mean aortic root diameter of $41 \pm 7 \mathrm{~mm}$ (range, 30-60 mm). Fifteen patients 
TABLE 1. Baseline patient characteristics and predisposing factors for aortic dissection

\begin{tabular}{lc}
\hline \multicolumn{1}{c}{ Variables } & Patients $(\mathbf{n}=\mathbf{3 1 9})$ \\
\hline Baseline patient characteristics & \\
Age, years, mean $\pm \mathrm{SD}$ & $63 \pm 11$ \\
Sex, female, $\mathrm{n}(\%)$ & $101(32)$ \\
$\mathrm{BSA}, \mathrm{m}^{2} ;$ mean $\pm \mathrm{SD}$ & $1.88 \pm 17.9$ \\
Hypertension, $\mathrm{n}(\%)$ & $232(73)$ \\
Diabetes mellitus, $\mathrm{n}(\%)$ & $61(19)$ \\
COPD, $\mathrm{n}(\%)$ & $57(18)$ \\
Chronic renal failure, $\mathrm{n}(\%)$ & $54(17)$ \\
Peripheral vascular disease, $\mathrm{n}(\%)$ & $70(22)$ \\
Previous stroke, $\mathrm{n}(\%)$ & $9(3)$ \\
Previous heart disease, $\mathrm{n}(\%)$ & $45(14)$ \\
Predisposing factors, $\mathrm{n}(\%)$ & \\
Marfan syndrome & $5(1.5)$ \\
Bicuspid aortic valve & $11(3.4)$ \\
Previous cardiac surgery & $7(2.2)$ \\
\hline SD, Standard deviation; $B S A$, body surface area; COPD, chronic obstructive pulmo- \\
nary disease.
\end{tabular}

had an aortic root diameter $>45 \mathrm{~mm}$ (mean diameter, $51.6 \pm$ $2.4 \mathrm{~mm}$; range, $46-60 \mathrm{~mm}$ ), but were not reoperated because of their advanced age ( $>85$ years) and/or associated comorbidities (14 patients) with increased operative risk (mean logistic EuroSCORE, $18.6 \% \pm 2.3 \%$ ), or because they refused the operation (1 patient). Actuarial freedom from an aortic root diameter $>50 \mathrm{~mm}$ is shown in Figure 3 .

\section{DISCUSSION}

This study shows the 23-year follow-up clinical, surgical, and echocardiographic results of 319 patients who underwent supracoronary ascending aorta replacement for AAD. We demonstrated that native aortic root preservation is effective long term, with low reoperation and aortic root dilatation rates.

TABLE 2. Surgical data

\begin{tabular}{lc}
\hline \multicolumn{1}{c}{ Variables } & Patients $(\mathbf{n}=\mathbf{3 1 9})$ \\
\hline CPB time, min; mean $\pm \mathrm{SD}$ & $183 \pm 70$ \\
ACC time, min; mean $\pm \mathrm{SD}$ & $110 \pm 40$ \\
DHCA time, min; mean $\pm \mathrm{SD}$ & $36 \pm 21$ \\
DHCA temperature, ${ }^{\circ} \mathrm{C} ;$ mean $\pm \mathrm{SD}$ & $23 \pm 1.2$ \\
Aortic root-associated procedures, $\mathrm{n}$ & \\
$\quad$ Mechanical AVR & 2 \\
Biological AVR & 19 \\
Distal procedures, $\mathrm{n}$ & \\
Hemiarch replacement & 173 \\
Total arch replacement & 37 \\
Proximal descending aorta replacement & 2 \\
Thoracic aortic stent grafting & 4 \\
Other associated procedures, $\mathrm{n}$ & 20 \\
CABG & 2 \\
Mitral valve repair & \\
\hline$C P B$, Cardiopulmonary bypass; $S D$, standard deviation; $A C C$, aortic crossclamp; \\
$D H C A$, deep hypothermic circulatory arrest; $A V R$, aortic valve & replacement; \\
$C A B G$, coronary artery bypass grafting. &
\end{tabular}

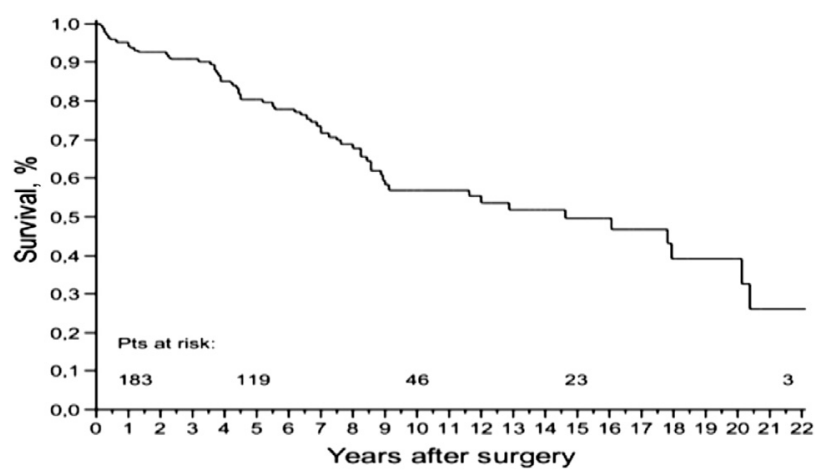

FIGURE 1. Actuarial survival after surgery for acute type A aortic dissection among 210 discharged patients. Pts, Patients.

Acute type A aortic dissection is a challenging operation not only because of technical difficulties, but also because of difficulties in determining whether an aggressive approach or a timesaving operation is required in an emergency setting. The primary goal is to save the patient's life by performing a safe operation; the secondary aim is to guarantee long-term freedom from reoperation. Supracoronary replacement of the ascending aorta with root reconstruction is one of the most commonly adopted conservative approaches used during surgery for AAD. The drawback of this conservative technique is that the residual aortic root might predispose the patient to proximal aneurysm formation that will then require reoperation on the aortic root and/or the aortic valve during the late postoperative period. ${ }^{1}$ On the other hand, a more aggressive approach has to be weighed against potential failure of the conservative technique. In this case, complete root replacement using a composite graft prevents future aneurysmal

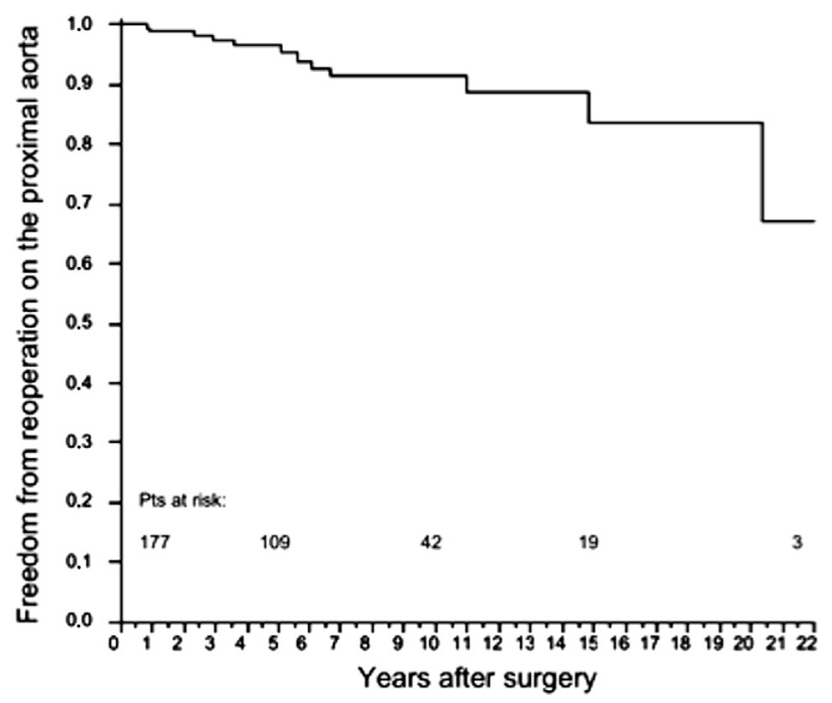

FIGURE 2. Actuarial freedom from aortic root replacement after surgery for acute type A aortic dissection with aortic root preservation. Pts, Patients. 


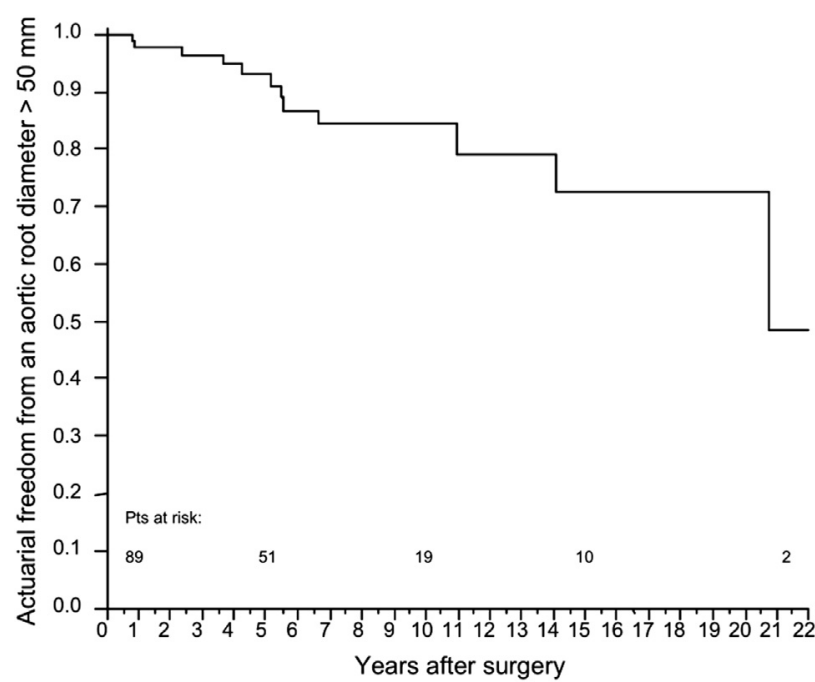

FIGURE 3. Actuarial freedom from aortic root diameter $>50 \mathrm{~mm}$ after surgery for acute type A aortic dissection with aortic root preservation at latest follow-up. Pts, Patients.

formations and recurrent dissection of the aortic root, ${ }^{3,8}$ but the higher operative risk resulting from the increased technical difficulty and reduced tissue quality of the dissected aorta does not justify extensive use of the procedure. ${ }^{2}$ The key issue of the current study was whether aortic root preservation yields acceptable long-term survival and a low incidence of further proximal reoperation.

Halstead and colleagues ${ }^{9}$ concluded that all patients with an aortic root with a proximal diameter $>3.5 \mathrm{~cm}$ should be considered for composite replacement even in the absence of coronary dissection or significant aortic insufficiency. In a series including 315 patients who underwent surgery to treat AAD, Tan and associates ${ }^{10}$ showed, using multivariate analyses, that an aortic annulus $>27 \mathrm{~mm}$, dissection of the left coronary artery, and use of surgical glue for aortic root reconstruction are independent risk factors for later aortic root reoperation. In a similar study, Casselman and coworkers $^{11}$ found the same independent risk factors for later aortic root reoperation as those reported by Tan and associates, ${ }^{10}$ with freedom from aortic root reoperation reported by $95 \%, 89 \%$, and $69 \%$ of patients at 1,5 , and 10 years, respectively. Similar freedom from proximal operation results after a 10-year follow-up was reported by Sabik and colleagues. ${ }^{12}$ These reports concluded that long-term results following aortic root reoperation were not significantly different between patients with a native aortic valve and patients who underwent aortic valve replacement. Moreover, they showed that the high freedom from failure of supracoronary reconstruction should lead surgeons to opt for a conservative approach.

In our longer follow-up, we report an acceptable survival among discharged patients, with an in-hospital mortality rate of $34 \%$. Although some groups with extensive experience have reported operative mortalities as low as $6 \%$ to $9 \%,{ }^{13,14}$ a figure of about $20 \%$ to $30 \%{ }^{5,14,15}$ with a decrease to $15.3 \%$ during the past 2 years between 2008 and 2010, as achieved by our group, is perhaps more realistic for most surgical units dealing with this kind of emergency surgery. Whether the type of proximal repair affects hospital mortality is still debated. Recently, Nakajima and associates ${ }^{16}$ reported a low mortality rate with the conservative root approach, which is in contrast with results of previous studies that show that hospital mortality depends more on clinical condition on admission and extension of surgical maneuvers to the aortic arch than on the type of proximal repair. ${ }^{17-19}$ In our experience, it is difficult to determine whether the conservative root approach has a low operative mortality rate because data are biased by the high proportion of patients who require DHCA and arch surgery. The impact of these procedures on late survival has not been demonstrated clearly. ${ }^{20} \mathrm{We}$ performed DHCA with replacement of the proximal aorta in a large series of patients, based on the preference of the surgeon, with the aim of exploring the arch, removing the site of clamping, and improving late survival.

Twelve patients were reoperated for aortic root dilatation, and 2 of these patients died after reoperation. Indications for proximal reoperations included isolated aortic root dilatation in 2 patients (mean diameter, $5.2 \pm 2.3$ $\mathrm{mm}$ ) and root dilatation (mean diameter, $5.4 \pm 2.1 \mathrm{~mm}$ ) with associated aortic regurgitation $(>2+)$ in 10 patients. The proportion of patients free of proximal reoperation was $99 \%, 97 \%, 93 \%, 83 \%$, and $66 \%$ at $1,5,10,15$, and 20 years, respectively. Multivariate Cox regression revealed that significant risk factors for proximal reoperation were age $<60$ years $(P=.005 ; \mathrm{RR}, 1.94)$ and Marfan syndrome $(P=.011 ; \mathrm{RR}, 2.76)$; thus, patients with Marfan syndrome or patients $<60$ years have a higher risk of reoperation when supracoronary replacement is performed. Moreover, at latest follow-up, 15 patients had an aortic root diameter of $>45$ $\mathrm{mm}$ but were not reoperated as a result of advanced age (>85 years) and/or associated comorbidities (14 patients) with increased operative risk (mean logistic EuroSCORE, $18.6 \% \pm 2.3 \%$ ), or because they refused surgery (1 patient).

On the basis of our findings, we think that the best strategy for AAD must take into account not only the dimension of the aortic root and aortic valve integrity, but also the feasibility of the surgery, the age of the patient, and the consequent life expectancy. In elderly patients, this minimalist approach is even more justified, considering that a more aggressive strategy neither eliminates the risk of proximal operations nor reduces the rate of potential valve-related complications. ${ }^{21}$ Moreover, this conservative approach is a much less demanding technique and is therefore more accessible and reproducible by surgeons with varying degrees of aortic surgery experience. ${ }^{22-24}$ 


\section{Limitations}

Our study has some limitations. The current series was a retrospective analysis of the surgical results of 14 different surgeons over a 23-year period. Because of the length of the study period, echocardiographic data were not available for the earliest series of patients. The high in-hospital mortality reflects the long period of this observational study and the consequent evolution of the preoperative diagnostic tools and postoperative treatments in our intensive care unit. Although we attempted to account for factors that had changed during this period (year of operation and surgeon experience), some issues may not be reflected in the multivariate analysis. Surgeons operated on the patients included in this study using a relatively uniform approach, but the decision to use a conservative approach was made intraoperatively and depended on the surgeon's preference and estimation of its feasibility. Therefore, a comparison between patients receiving root replacement and patients receiving supracoronary reconstruction would be biased because of the surgeon's discretion in intraoperative decision making and the inability to adjust the multivariate regression to account for the personal preferences of the surgeon. Moreover, although our data are reliable, a further possible statistical limitation could be the low number of events (reoperation) for the regression analysis and the low number of identified risk factors. Further studies are required to confirm these results.

\section{CONCLUSIONS}

Our 23-year follow-up study confirms that replacement of the ascending aorta with root preservation for AAD shows long-term effectiveness with low reoperation and aortic root dilatation rates. In younger patients, potential aortic root dilatation is a concern and should influence the surgical approach by using a more aggressive strategy.

\section{References}

1. Niederhäuser U, Künzli A, Seifert A, Schmidli J, Lachat M, Zund G, et al Conservative treatment of the aortic root in acute type A dissection. Eur J Cardiothorac Surg. 1999; 15:557-63.

2. Concistrè G, Casali G, Santaniello G, Montaldo A, Fiorani B, Dell'Aquila AM, et al. Reoperation after surgical correction of acute type A aortic dissection: risk factor analysis. Ann Thorac Surg. 2012;93:450-5.

3. Ergin MA, McCullough J, Galla JD, Lansman SL, Griepp RB. Radical replacement of the aortic root in acute type A dissection: indications and outcome. Eur J Cardiothorac Surg. 1996;10:840-4; discussion 845.

4. Westaby S, Katsumata T, Freitas E. Aortic valve conservation in acute type A dissection. Ann Thorac Surg. 1997;64:1108-12.

5. Kuroczynski W, Dohmen G, Hake U, Hilker M, Choi YH, Anaraki S, et al. Aortic valve preservation in acute type A dissection: mid-term results. J Heart Valve Dis. 2001;10:779-83.
6. Lai DT, Miller DC, Mitchell RS, Oyer PE, Moore KA, Robbins RC, et al. Acute type A aortic dissection complicated by aortic regurgitation: composite valve graft versus separate valve graft versus conservative valve repair. $J$ Thorac Cardiovasc Surg. 2003;126:1978-86.

7. Sheikhzadeh S, Kusch ML, Rybczynski M, Kade C, Keyser B, Bernhardt AM, et al. A simple clinical model to estimate the probability of Marfan syndrome. Q J Med. 2012;105:527-35.

8. Kazui T, Yamashita K, Terada H, Washiyama N, Suzuky T, Ohkura K, et al. Late reoperation for proximal aortic and arch complications after previous composite graft replacement in Marfan patients. Ann Thorac Surg. 2003;76: 1203-7.

9. Halstead JC, Meier M, Etz C, Spielvogel D, Bodian C, Wurm M, et al. The fate of the distal aorta after repair of acute type A aortic dissection. J Thorac Cardiovasc Surg. 2007; 133:127-35.

10. Tan ME, Morshuis WJ, Dossche KM, Kelder JC, Waanders FG, Schepens MA. Long-term results after 27 years of surgical treatment of acute type A aortic dissection. Ann Thorac Surg. 2005;80:523-9.

11. Casselman FP, Tan MESH, Vermeulen FEE, Kelder JC, Morshuis WJ, Schepens MA. Durability of aortic valve preservation and root reconstruction in acute type A aortic dissection. Ann Thorac Surg. 2000;70: 1227-33.

12. Sabik JF, Lytle BW, Blackstone EH, McCarthy PM, Loop FD, Cosgrove DM. Long-term effectiveness of operations for ascending aortic dissections. J Thorac Cardiovasc Surg. 2000;119:946-62.

13. Fann JI, Glower DD, Miller DC, Yun KL, Rankin JS, White WD, et al. Preservation of aortic valve in type A aortic dissection complicated by aortic regurgitation. J Thorac Cardiovasc Surg. 1991;102:62-73.

14. Von Segesser LK, Lorenzetti E, Lachat M, Niederhäuser U, Schönbeck M, Vogt PR, et al. Aortic valve preservation in acute type A dissection: is it sound? J Thorac Cardiovasc Surg. 1996;111:381-90.

15. Mazzucotelli JP, Deleuze PH, Baufreton C, Duval AM, Hillion ML, Loisance DY, et al. Preservation of the aortic valve in acute aortic dissection: long-term echocardiographic assessment and clinical outcome. Ann Thorac Surg. 1993;55:1513-7.

16. Nakajima T, Kawazoe K, Kataoka T, Kin H, Kazui T, Okabayashi H, et al. Midterm results of aortic repair using a fabric neomedia and fibrin glue for type A acute aortic dissection. Ann Thorac Surg. 2007;83:1615-20.

17. Halstead JC, Spielvogel D, Meier DM, Rinke S, Bodian C, Malekan R, et al. Composite aortic root replacement in acute type A dissection: time to rethink the indications? Eur J Cardiothorac Surg. 2005;27:626-32.

18. Santini F, Montalbano G, Casali G, Messina A, Iafrancesco M, Luciani GB, et al. Clinical presentation is the main predictor of in-hospital death for patients with acute type A aortic dissection admitted for surgical treatment: a 25 years experience. Int J Cardiol. 2007;115:305-11.

19. Pansini S, Gagliardotto PV, Pompei E, Parisi F, Bardi G, Castenetto E, et al. Early and late risk factors in surgical treatment of acute type A aortic dissection. Ann Thorac Surg. 1998;66:779-84.

20. Lai DT, Robbins RC, Mitchell RS, Moore KA, Oyer PE, Shumway NE, et al. Does profound hypothermic circulatory arrest improve survival in patients with acute type A aortic dissection? Circulation. 2002;106:218-28.

21. Moon MR, Sundt TM III, Pasque MK, Barner HB, Huddleston CB, Damiano RJ Jr, et al. Does the extent of proximal or distal resection influence outcome for type A dissections? Ann Thorac Surg. 2001;71:1244-9.

22. Schäfers HJ, Kunihara T. Towards safer reoperations: special aspects in aortic dissection. Eur J Cardiothorac Surg. 2008;33:700-2.

23. Geirsson A, Bavaria JE, Swarr D, Keane MG, Woo YJ, Szeto WY, et al. Fate of residual distal and proximal aorta after acute type A dissection repair using a contemporary surgical reconstruction algorithm. Ann Thoracic Surg. 2007;84: 1955-64.

24. Piccardo A, Regesta T, Pansini S, Dell'Aquila AM, Concistrè G, Martinelli L, et al. Fate of the aortic valve after root reconstruction in type A aortic dissection: a 20-year follow up. J Heart Valve Dis. 2009;18:507-13. 